\title{
Proceeding Paper \\ Optical Biosensor for the Detection of Hydrogen Peroxide in Milk ${ }^{+}$
}

\author{
Helena Vasconcelos ${ }^{1,2, *}$, Ana Matias ${ }^{2}\left(\mathbb{D}\right.$, Pedro Jorge ${ }^{2}\left(\mathbb{D}\right.$, Cristina Saraiva ${ }^{1} \mathbb{(}$, João Mendes ${ }^{2}\left(D\right.$, João Araújo ${ }^{2}$, \\ Bernardo Dias $^{2}$, Paulo Santos ${ }^{2}\left(\mathbb{D}\right.$, José M. M. M. Almeida ${ }^{2,3}$ (D) and Luís C. C. Coelho ${ }^{2}$ (D) \\ 1 School of Agrarian and Veterinary Sciences, University of Trás-os-Montes e Alto Douro, \\ 5001-801 Vila Real, Portugal; crisarai@utad.pt \\ 2 INESC TEC-Institute for Systems and Computer Engineering, Technology and Science and Faculty of Sciences, \\ University of Porto, 4169-007 Porto, Portugal; ana.b.teixeira@inesctec.pt (A.M.); pedro.jorge@inesctec.pt (P.J.); \\ joaomendes.quimica@gmail.com (J.M.); up201703919@edu.fc.up.pt (J.A.); up201103504@edu.fc.up.pt (B.D.); \\ paulo.s.santos@inesctec.pt (P.S.); jmmma@utad.pt (J.M.M.M.A.); lcoelho@inesctec.pt (L.C.C.C.) \\ 3 Department of Physics, School of Science and Technology, University of Trás-os-Montes e Alto Douro, \\ 5001-801 Vila Real, Portugal \\ * Correspondence: helenavasconcelos88@gmail.com \\ + Presented at the 1st International Electronic Conference on Chemical Sensors and Analytical Chemistry, \\ 1-15 July 2021; Available online: https:/ / csac2021.sciforum.net/.
}

check for updates

Citation: Vasconcelos, H.; Matias, A.; Jorge, P.; Saraiva, C.; Mendes, J.;

Araújo, J.; Dias, B.; Santos, P.;

Almeida, J.M.M.M.; Coelho, L.C.C.

Optical Biosensor for the Detection of

Hydrogen Peroxide in Milk.

Chem. Proc. 2021, 5, 55. https:// doi.org/10.3390/CSAC2021-10466

Academic Editors: Huangxian Ju and Elena Benito Peña

Published: 30 June 2021

Publisher's Note: MDPI stays neutral with regard to jurisdictional claims in published maps and institutional affiliations.

Copyright: (c) 2021 by the authors. Licensee MDPI, Basel, Switzerland. This article is an open access article distributed under the terms and conditions of the Creative Commons Attribution (CC BY) license (https:// creativecommons.org/licenses/by/ $4.0 /)$.

\begin{abstract}
Over the years, the food industry's concern to provide safe food that does not cause harm or illness to consumers has increased. The growing demand for the detection of compounds that can contaminate food is increasingly important. Hydrogen peroxide is frequently used as a substance to control the growth of microorganisms in milk, thus increasing its shelf life. Here, a strategy is presented for the detection of hydrogen peroxide as a milk adulterant, using a single shot membrane sensor. The lowest concentration measured with this technique was $0.002 \% w / w$ of $\mathrm{H}_{2} \mathrm{O}_{2}$ in semi-fat milk.
\end{abstract}

Keywords: chemiluminescence; hydrogen peroxide; optical sensor; food safety; food fraud; quality assessment

\section{Introduction}

Milk is one of the most complete foods for humans, containing nutrients including carbohydrates, proteins, fats, minerals, and vitamins [1].

Owing to its rich composition, milk becomes a substrate for the growth of undesirable microorganisms that can easily deteriorate the product. To prevent this from happening, prohibited substances are fraudulently added [2]. Hydrogen peroxide $\left(\mathrm{H}_{2} \mathrm{O}_{2}\right)$, hypochlorite, formaldehyde, potassium dichromate, and salicylic acid are examples of substances used as adulterants that need monitoring and quality control as they are toxic to humans [3].

In the case of $\mathrm{H}_{2} \mathrm{O}_{2}$, it is widely used in the dairy industry as an antimicrobial agent, thus helping to preserve raw milk in the absence of refrigeration [4]. Despite its conventional use, when added to milk, $\mathrm{H}_{2} \mathrm{O}_{2}$ can cause a decrease in the nutritional value of the food due to the destruction of vitamins $\mathrm{A}$ and $\mathrm{E}$, which generate reactive and cytotoxic oxygen species, including hydroxyl radicals, that can initiate oxidation and damage nucleic acids, lipids, and proteins. Consequently, when ingested, milk can lead to negative effects on the health of the population, especially in immunocompromised people [2,4].

In the USA, hydrogen peroxide is used in cheese production in concentrations up to $0.05 \% w / w$, however, in other countries, its addition is prohibited due to its toxic effects. A peroxide concentration $>0.1 \% w / w$ has been proven to induce cancer in the duodenum of mice and present short-term genotoxicity [3].

Here, a study is presented for the detection and quantification of $\mathrm{H}_{2} \mathrm{O}_{2}$ using a chemiluminescence technique. A small, low-cost hydroxyethyl cellulose sensitive membrane combined with a high-sensitive photodetector is used to measure $\mathrm{H}_{2} \mathrm{O}_{2}$ concentrations in semi-fat milk samples. 


\section{Materials and Methods}

The sensing methodology is based on the detection of a luminescence signal from the chemical reaction within a solid membrane produced with hydroxyethyl cellulose (HEC, Sigma Aldrich, Taufkirchen, Germany), luminol, sodium phosphate, cobalt (II) chloride hexahydrate, sodium lauryl sulphate (SLS), and ethylenediaminetetraacetic acid (EDTA).

The procedure established by Omanovic-Miklicanin [5] was refined to establish experimental protocols. For the determination of $\mathrm{H}_{2} \mathrm{O}_{2}$ in very low concentrations, the sensor sensitivity should be as high as possible. Therefore, the systematic optimization of the membrane was necessary. Only one constituent was varied at a time, keeping the remaining constituents unchanged. After membrane optimization, the final concentrations of these constituents were set to luminol $(0.2 \mathrm{mg})$, sodium phosphate $(8.6 \mathrm{mg})$, SLS $(60 \mu \mathrm{L}$, $34.36 \mathrm{mmol} / \mathrm{L})$, cobalt hydroxide $(100 \mu \mathrm{L}, 5.0 \mathrm{mmol} / \mathrm{L})$, EDTA $(2 \mu \mathrm{L}, 20 \mu \mathrm{mol} / \mathrm{L})$, and HEC $(150 \mathrm{mg})$ was added to $10 \mathrm{~mL}$ of Milli-Q ${ }^{\circledR}$ water.

The membrane solution was placed on a magnetic stirrer for $30 \mathrm{~min}$. Individual 3D printed cups were used, and $1000 \mu \mathrm{L}$ of membrane solution was added and dried for $4 \mathrm{~h}$ $\left(\mathrm{T}=70{ }^{\circ} \mathrm{C}\right)$. After drying, the membranes were stored in a desiccator under a vacuum. For the measurement procedure, the membrane was placed directly onto the membrane holder on top of the detector. The light emission was measured by adding $500 \mu \mathrm{L}$ of the sample solution.

For straight and rapid spectrophotometric $\mathrm{H}_{2} \mathrm{O}_{2}$ detection, a detection module was built containing a highly sensitive detection system with a photodiode (model S8746-01 Hamamatsu Japan), a dedicated amplification system with variable gain, and an embed controlling unit. The sensitive optoelectronic system was isolated inside of a custom-made $3 \mathrm{D}$ printed case allowing the easy replacement of the sensing membrane and allowing the sample pipetting, preventing the detection of the ambient light. This module was powered with a low noise power source, and the data was acquired and analyzed with a user-friendly graphical interface (GUI) and a raspberry pi (Figure 1).

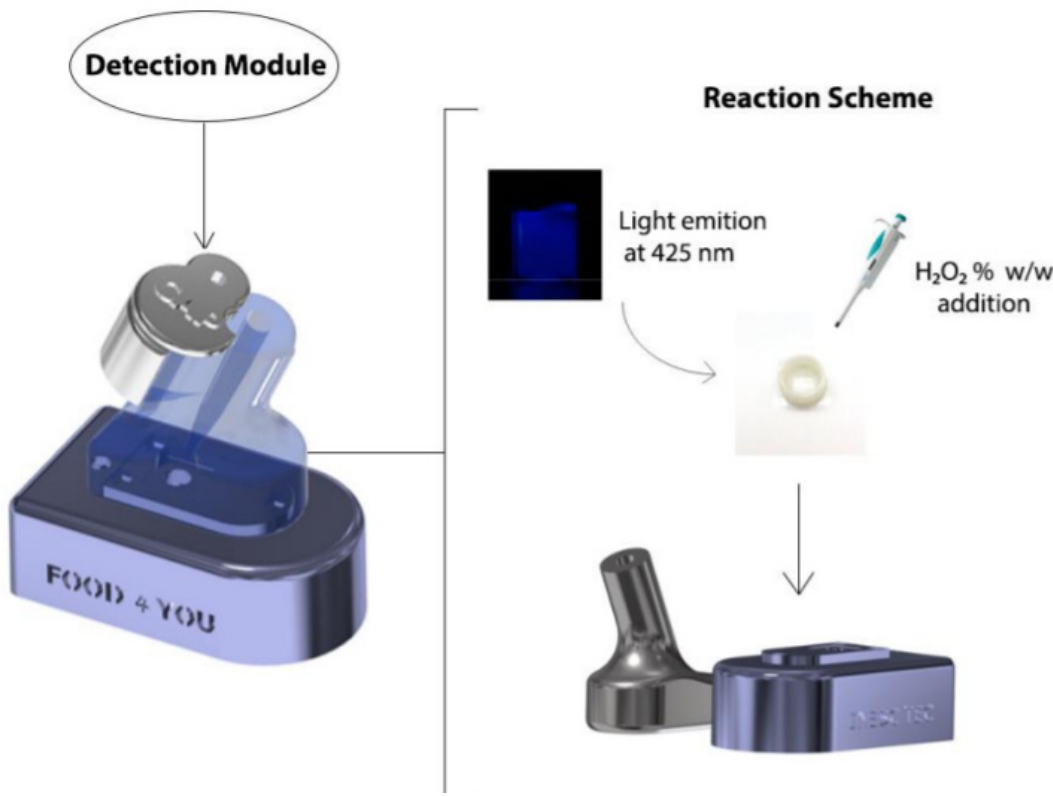

Figure 1. Schematic diagram of the analyte detection.

\section{Results and Discussion}

Semi-fat milk samples were adulterated with $\mathrm{H}_{2} \mathrm{O}_{2}$ concentrations from $0.001 \% w / w$ to $0.006 \% w / w$ by diluting a standard $30 \% w / w$ solution of $\mathrm{H}_{2} \mathrm{O}_{2}$. The variation of the chemiluminescent intensity is presented in Figure 2 for all samples, together with the time integral of the decaying chemiluminescent signal for each $\mathrm{H}_{2} \mathrm{O}_{2}$ concentration. 


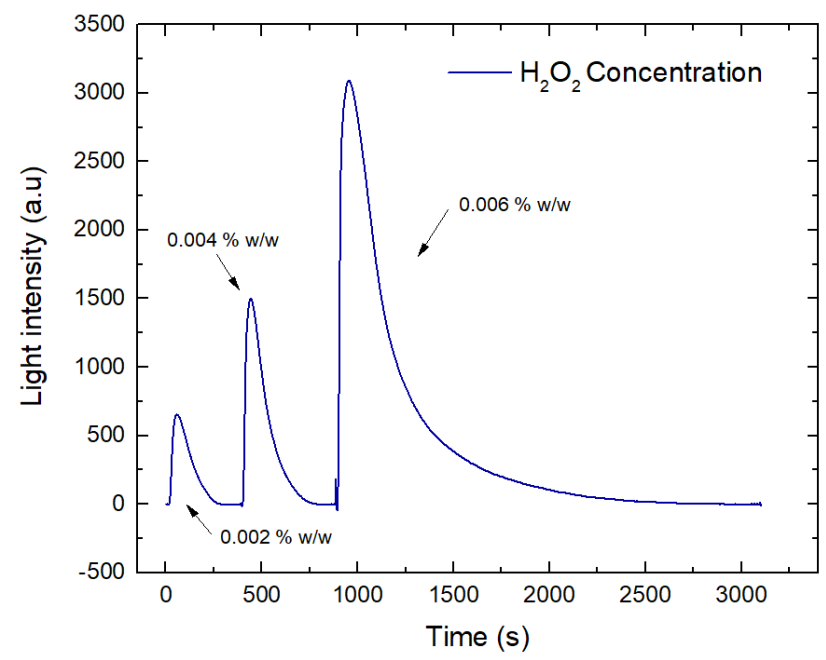

(a)

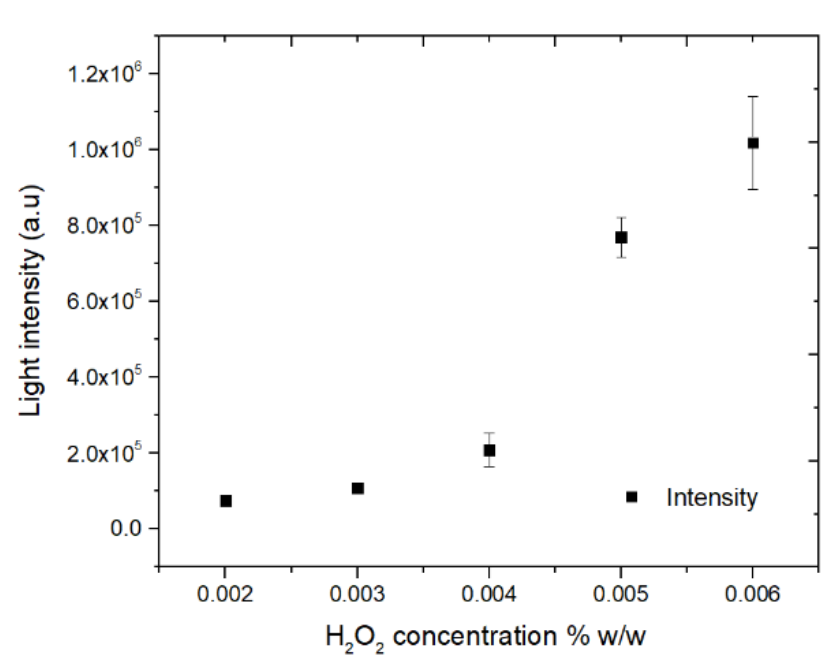

(b)

Figure 2. (a) Variation of the intensity of the light emission for the concentrations of 0.002, 0.004, and $0.006 \% w / w$ as a function of time; (b) Time integral of the decay time for each $\mathrm{H}_{2} \mathrm{O}_{2}$ concentration.

Taking into consideration that $0.05 \% w / w$ of $\mathrm{H}_{2} \mathrm{O}_{2}$ is the defined limit for the FDA in milk for cheese production [6], the developed sensor would be suitable for determinations of $\mathrm{H}_{2} \mathrm{O}_{2}$ as a fraud controller in milk samples within the legal limits of different countries. Moreover, to achieve a more practical approach to the commonly time-consuming sample preparation methods, the pre-treatment step was successfully eliminated. In fact, the optimized sensor requires minimal solvent use and waste production. When compared with other methods available for the determination of $\mathrm{H}_{2} \mathrm{O}_{2}$ presence in milk, this portable biosensor is an easy and reliable method that ensures the required sensitivity while offering a low time of analysis and no need for additional laboratory equipment.

The methodology developed and optimized demonstrates that it is possible to detect very low concentrations of $\mathrm{H}_{2} \mathrm{O}_{2}$ (down to $0.001 \% w / w$ in an aqueous system). As the $\mathrm{H}_{2} \mathrm{O}_{2}$ concentration increased, the intensity of the emitted light and the reaction time increased. Low limits of detection were achieved, thus indicating the applicability of this assay to real samples exhibiting the required sensitivity for the analytical determination of $\mathrm{H}_{2} \mathrm{O}_{2}$ in biological samples such as milk.

In this work, the reaction of $\mathrm{H}_{2} \mathrm{O}_{2}$ and luminol catalyzed by cobalt hydroxide was used to detect $\mathrm{H}_{2} \mathrm{O}_{2}$ in milk; however, another spectrophotometric method was described by Lima et al. [2] for the detection of $\mathrm{H}_{2} \mathrm{O}_{2}$ in milk, using the reaction between hydrogen peroxide and guaiacol, catalyzed by peroxidase, producing a red product, where a low detection limit was obtained.

\section{Conclusions}

The proposed sensor provided to be a rapid, cost-effective, and environmentally friendly approach for the determination of hydrogen peroxide as a milk adulterant. This optimized and validated method has a very good linearity range when the sample is in its liquid state, where concentrations of $\mathrm{H}_{2} \mathrm{O}_{2}$ as low as $0.001 \% w / w$ can be detected with good repeatability. As a practical application for this methodology under controlled conditions, an adulterated milk sample was analyzed. Concentrations of $\mathrm{H}_{2} \mathrm{O}_{2}$ of $0.002 \% w / w$ to $0.006 \%$ were detected, and the method was calibrated for semi-fat milk, proving that the limit of detection and linearity range of the proposed method are suitable for the analysis of milk samples in loco, which can add value to the food fraud department. Moreover, the reagents required are commonly used in analytical laboratories, are inexpensive, and can be consumed in low amounts $(500 \mu \mathrm{L})$, thus resulting in negligible and non- 
toxic waste generation. In addition to the mentioned advantageous features, the proposed method validation is comparable to those found in the literature.

Supplementary Materials: The supporting information can be downloaded at: https:/ /www.mdpi. com/article/10.3390/CSAC2021-10466/s1.

Author Contributions: Writing-review and editing, H.V., A.M., J.M., J.A., B.D. and P.S.; supervision, L.C.C.C., P.J., C.S. and J.M.M.M.A. All authors have read and agreed to the published version of the manuscript.

Funding: This research was funded by National Funds through the Portuguese funding agency, FCT_Fundação para a Ciência e a Tecnologia, within project UIDB/50014/2020. Helena Vasconcelos acknowledges the support from FCT grant SFRH/BD/120064/2016 and Luís Coelho acknowledges the support from FCT research contract grant CEECIND/00471/2017.

Institutional Review Board Statement: Not applicable.

Informed Consent Statement: Not applicable.

Acknowledgments: This work was financed by National Funds through the Portuguese funding agency, FCT—Fundação para a Ciência e a Tecnologia, within project UIDB/50014/2020. Helena Vasconcelos acknowledges the support from FCT grant SFRH/BD/120064/2016 and Luís Coelho acknowledges the support from FCT research contract grant CEECIND/00471/2017.

Conflicts of Interest: The authors declare no conflict of interest.

\section{References}

1. Handford, C.E.; Campbell, K.; Elliott, C.T. Impacts of Milk Fraud on Food Safety and Nutrition with Special Emphasis on Developing Countries. Compr. Rev. Food Sci. Food Saf. 2016, 15, 130-142. [CrossRef] [PubMed]

2. Lima, L.S.; Rossini, E.L.; Pezza, L.; Pezza, H.R. Bioactive Paper Platform for Detection of Hydrogen Peroxide in Milk. Spectrochim. Acta-Part A Mol. Biomol. Spectrosc. 2020, 227, 117774. [CrossRef] [PubMed]

3. Lima, M.J.A.; Sasaki, M.K.; Marinho, O.R.; Freitas, T.A.; Faria, R.C.; Reis, B.F.; Rocha, F.R.P. Spot Test for Fast Determination of Hydrogen Peroxide as a Milk Adulterant by Smartphone-Based Digital Image Colorimetry. Microchem. J. 2020, 157, 105042. [CrossRef]

4. Robinson, B.R.; D'Amico, D.J. Hydrogen Peroxide Treatments for the Control of Listeria Monocytogenes on High-Moisture Soft Cheese. Int. Dairy J. 2021, 114, 104931. [CrossRef]

5. Omanovic-Miklicanin, E.; Valzacchi, S. Development of New Chemiluminescence Biosensors for Determination of Biogenic Amines in Meat. Food Chem. 2017, 235, 98-103. [CrossRef] [PubMed]

6. CFR-Code of Federal Regulations Title 21. Available online: https://www.accessdata.fda.gov/scripts/cdrh/cfdocs/cfcfr/ cfrsearch.cfm (accessed on 6 June 2021). 